Hamline University

DigitalCommons@Hamline

School of Education and Leadership Student Capstone Projects

Spring 2021

\title{
Code-Switching in the Classroom
}

Rebecca Maki

Follow this and additional works at: https://digitalcommons.hamline.edu/hse_cp

Part of the Education Commons

\section{Recommended Citation}

Maki, Rebecca, "Code-Switching in the Classroom" (2021). School of Education and Leadership Student Capstone Projects. 640.

https://digitalcommons.hamline.edu/hse_cp/640

This Capstone Project is brought to you for free and open access by the School of Education and Leadership at DigitalCommons@Hamline. It has been accepted for inclusion in School of Education and Leadership Student Capstone Projects by an authorized administrator of DigitalCommons@Hamline. For more information, please contact digitalcommons@hamline.edu. 


\title{
Code-Switching in the Classroom
}

\author{
by \\ Rebecca Maki
}

\begin{abstract}
A capstone project submitted in partial fulfillment of the requirements for the degree of Master of Arts in Teaching English to Speakers of Other Languages
\end{abstract}

\author{
Hamline University \\ Saint Paul, Minnesota
}

May 2021

\section{Capstone Project Facilitator: Julia Reimer}

Content Expert: Laura Gehlhar

Peer Reviewers: Jessica Gambrill, Peter Rom 
TABLE OF CONTENTS

CHAPTER ONE: Introduction $\quad 4$

$\begin{array}{ll}\text { A Culture Shock } & 5\end{array}$

$\begin{array}{ll}\text { Choosing a Project } & 7\end{array}$

$\begin{array}{ll}\text { Summary } & 8\end{array}$

$\begin{array}{ll}\text { CHAPTER TWO: Literature Review } & 10\end{array}$

$\begin{array}{ll}\text { Background } & 10\end{array}$

$\begin{array}{ll}\text { Definition of Code-Switching } & 10\end{array}$

History of Code-Switching in the Classroom 13

Benefits of Code-Switching in the Classroom 14

$\begin{array}{ll}\text { Limitations of Code-Switching } & 16\end{array}$

$\begin{array}{ll}\text { The English-Only Model } & 19\end{array}$

$\begin{array}{ll}\text { Reading Comprehension } & 19\end{array}$

$\begin{array}{ll}\text { Writing Skills } & 22\end{array}$

$\begin{array}{ll}\text { Summary } & 26\end{array}$

CHAPTER THREE: Project Description 29

$\begin{array}{ll}\text { Project Overview } & 29\end{array}$

$\begin{array}{ll}\text { Setting } & 30\end{array}$

Research Framework 33

Implementation of Principles $\quad 35$

$\begin{array}{ll}\text { Session Content } & 36\end{array}$ 
Assessment

Summary

CHAPTER FOUR: Reflection and Conclusion

Reflections on the Process

Reflections on the Literature Review

Implications

Short Term Impact

Long Term Impact

Conclusion

REFERENCES

Appendix A: WIDA Performance Definitions Listening and Reading, Grades K-12 53

Appendix B: WIDA Performance Definitions Speaking and Writing, Grades K-12 54

Appendix C: Handout -Practical Applications of Students' First Languages in Your

Classroom 


\section{CHAPTER ONE}

\section{Introduction}

Educators today are paying much attention to the pedagogy and practices of Culturally Responsive Teaching (CRT), whereby teachers strive to become more understanding of and sensitive to students' cultures, and incorporate any and all strengths that students bring into the classroom. The goal of CRT is for classrooms to become inclusive and safe environments where learning can happen more readily (Hansen et al., 2013). As teachers serve students who are not just from a variety of cultures but also a variety of language backgrounds, a natural way to include CRT practices is to look for ways to add a student's first language (L1) into the lesson plan in intentional ways. Unfortunately, many teachers are not educated on the best practices for teaching English Language Learners (ELLs).

In order to help teachers create policies and lessons that use the L1 with research-based best practices, this capstone project will seek to answer the question: How can code-switching be used in the mainstream high school classroom taught by monolingual teachers to enhance learning for ELL students in the areas of writing fluency and reading comprehension?

In this chapter, I will narrate the journey I took to arrive at this research topic, explaining how my own culture shock at having arrived at a very diverse school motivated me to help students who undergo culture shock to a much greater extent. Following that, I explore how I arrived at the idea for this project. Finally, I will explain the significance of the question to the context of my school and to the research at large. 


\section{A Culture Shock}

My journey to this research question is a result of a series of unexpected developments in my professional life. I attended a small college that trains pastors and teachers for the ministry of a small Christian synod. Upon completing a teaching degree, the graduates are given a choice of finding a teaching position through the typical means (applying, interviewing, etc.) or getting assigned to a school within the synod. I chose to be assigned and was given a position as an English as a Second Language (ESL) teacher at a school outside of St. Paul, MN.

This school was more diverse than any I had seen before, and was a bit of a culture shock to me. Students came from around the world to study here, and the international students were motivated to learn English so that they could get into American universities and create the future they wanted for themselves. I had never been outside of the United States before, but here in my classroom were students from China, Japan, Vietnam, South Korea, Brazil, and Germany, undergoing a much greater culture shock than I will ever experience. I was excited to learn from them, but I was equally intimidated by the thought of teaching them, as my undergraduate degree in Communication Arts and Literature did not sufficiently prepare me for teaching ELLs.

Of course, my own culture shock cannot be compared to that of the students, who are willing to move halfway across the world, away from family and friends, away from their familiar culture and comforts, in order to reach their goals. Not only was the classroom experience much different than what they were accustomed to, but when they went "home" to the dormitories after class, they also were faced with a strange and new 
culture. It was clear that my students were struggling in this new environment, despite their strong motivation to do well.

In order to better teach my international students, I sought help from my colleagues on ELL best practices, but there were very few people in the school with the education or experience to help me. A couple teachers had taken a summer course in ELL methods, but none were true experts in ELL education. Those who did try to help me offered suggestions that were oftentimes based in anecdotes or conjecture, not in research. I couldn't even call on my own language learning experiences, as I hadn't taken a foreign language since high school. I floundered my way through the first couple years, watching my students suffer the consequences of my inexperience and lack of education. I knew something needed to change, and that I needed to be the ELL expert for our school.

During this time, my husband and I were homestay parents to one of the Korean students at our school. He was a motivated and intelligent student; he would work on his homework for twice as long as his American peers, but would still struggle to achieve the same grades. A strong memory I have is of sitting next to him, trying to work our way through annotating a poem. He needed to stop and look up words so often, the overall meaning of the text was completely lost to him. I finally asked him to look up a Korean translation of the poem and explain the meaning of the poem after reading the translation. I watched the dawning of realization on his face as he read the text in Korean, and when he was finished, we had a discussion about the text that was so much deeper than what he was capable of previously. A question formed in my mind: Isn't this type of discussion 
what the literature annotation all about? And if this discussion is the goal, are we holding our ELL students back by insisting that they do the entire activity in English?

I began my Masters education at Hamline University in the fall of 2018, and what I learned was immediately implemented in my classroom. I finally had resources that were research-based and student-focused. I could see that research-based best practices were so much more effective than what I had been doing, and I was extremely motivated to share those with my colleagues.

I also learned that many of the suggestions I had received from colleagues at my school were not supported by the research, and sometimes were even harmful to the educational or emotional state of the student. One of these harmful suggestions was an "English-only" classroom. I had heard the phrase "English only" be used so often at our school, I thought that it must be a wise and helpful policy. Through my education at Hamline, I quickly learned that "English-only" policies can alienate students from the teacher and each other, can hinder students in their education, and are extremely antiquated. One of my overarching goals at my school became to eliminate any "English-only" policies. On the way there, I knew that I needed to prove to my colleagues that students' first languages (L1s) could be used to great success in the classroom through code-switching.

\section{Choosing a Project}

While much research has been done to show the benefits of L1 use in the classroom, and best practices have been suggested, this research and best practices do not necessarily account for a teacher who cannot communicate in the students' L1s, as many 
of the best practices call for teachers to be able to be communicative in both languages. Assuming that these classrooms are led by monolingual teachers means that there are restrictions and limitations of code-switching in the classroom. For example, a teacher cannot ask a student to summarize a text in the student's L1 and be able to check that summary for understanding. Unfortunately, not much research has gone into this specific classroom environment. This project will aim to fill the gap in this research by applying research-based best practices to a classroom with a monolingual teacher. In order to communicate these best practices, I have created a series of professional development sessions that help teachers to learn, implement, and reflect on new techniques in the areas of reading comprehension and writing skills.

The reason I have focused on reading and writing in particular is twofold. One, this project is the first step into what I hope will be yearly professional development that focuses on teaching ELLs. These two areas are easily recognized as areas of struggle among ELLs, and so I want to start with the areas that I believe will get the most engagement from my colleagues. Two, these two areas are relevant across content areas, as all content areas require reading comprehension and writing skills to some extent.

By filling in the research gap, I hope to improve the educational experience of the international students at our school, aiding them on their way toward getting into American universities and achieving their dreams. This will also help the school to assure the parents of international students that the staff is educated in ELL best practices. I hope that this project will also be of help to my colleagues at the school, who want to provide an excellent education for their international students but are unsure of how to do 
so or harbor misconceptions on how to teach their ELL students in the most effective way. Ultimately, my goal is to eliminate "English-only" policies on our campus by showing our administration the benefits of code-switching.

\section{Summary}

This chapter began with the research question around which this project was designed. It then outlined the journey that I took in order to arrive at this project, and finished with a brief description of how the project was chosen and the rationale behind it.

In Chapter Two, I will review the literature surrounding code-switching, its history, and the research about how it can be used in writing and reading comprehension. In Chapter Three, I will outline the professional development project by explaining the project itself as well as the research that supports the format. In Chapter Four, I will reflect on the project as a whole, its potential for change and its limitations. I will then chart a map for where to go after this project in order to further my overarching goal of excellent education for ELL students at this school. 


\section{CHAPTER TWO}

\section{Literature Review}

In order create professional development which helps teachers create policies and lessons that use the $\mathrm{L} 1$ with research-based best practices, this capstone project will seek to answer the question: How can code-switching be used in the mainstream high school classroom taught by monolingual teachers to enhance learning for ELL students in the areas of writing and reading comprehension?

This literature review chapter will first define code-switching, then explore the history of code-switching in education. It will then discuss the benefits and limitations of code-switching, and the disadvantages of the English-only model, followed by a description of the research-based best practices for code-switching in the areas of reading comprehension and writing skills. The chapter will conclude by explaining the need for a specialized professional development in this area.

\section{Background}

\section{Definition of Code-Switching}

Code-switching (CS) is a grammatical practice, which has sociolinguistic implications. In The Oxford Handbook of Sociolinguistics, Wei (2013) outlined five different levels of code-switching: 1. Interference - when a word is taken from one language and attempted in the other language, but the result is neither an L1 word or an L2 (second language) word (e.g. "Toco el drum-es" ["I play the drums"]). One language is "interfering" with the form of the other. 2. Transfer - using a colloquialism from one language in another, where the colloquialism is not used (e.g. "I don't believe you; you're 
taking my hair"). 3. Inter-speaker - when two speakers maintain their own language while speaking to each other; each understands the other, but neither is producing two languages (e.g. Speaker one: “Hi, how are you?” Speaker two: “Estoy bien, gracias. ¿Y usted?" [“I'm good, thanks. And you?"]). 4. Inter-clausal/inter-sentential - when a user switches languages between clauses or sentences (e.g. "I love this painting. Es una pintura hermosa. I think es una O'Keefe ¿sí?" ["It's a beautiful painting. I think it's an O' Keefe, yes?']) 5. Morphological - when a user switches between languages within a word (e.g. "I am comer-ing" ["eating"]).

MacSwan (2016) had a more narrow definition that closely relates to type four above. He defined code-switching as when a user switches lexical or morphological items, like substituting a noun phrase in the L1 in a sentence with a noun phrase in the second language (L2) (e.g. "Como se dice bat cave en Español?” [How do you say - bat cave - in Spanish?]) or mixing morphemes in the L1 and L2 (e.g. "I'm comer-ing" [I'm eat-ing]). He distinguishes code-switching from borrowing, where a word that was originally used in the L1 is now fully used and understood in the L2 lexicon (e.g. "kindergarten" is a German word that English has borrowed and integrated into the English lexicon as a whole). In code-switching, according to MacSwan, the L1 word, phrase, or morpheme is not integrated into the user's lexicon for the L2 (or vice versa). The user still distinguishes each language in their internal lexicons for each language.

Kamwangamalu (2010) defines code-switching as "the intersentential alternating use of two or more languages or varieties of a language in the same speech situation" (p. 116), broadening code-switching to include users switching within a conversation or 
other communication. For the purposes of this capstone, I will define code-switching as the phenomenon where a user is combining the L1 and English, whether with morphemes, phrases, or clauses. This definition is similar to Kamwangamalu's definition and Wei's levels 4 and 5. I will also assume, like MacSwan, that borrowing is not code-switching.

On a sociolinguistic level, code-switching takes place in several contexts. In his book on discourse strategies, Gumperz (1984) defined these contexts as situational and metaphorical. While this dichotomy has been questioned since 1984 (Kamwangamalu, 2010), this is still a useful way to explain what prompts code-switching. Situational contexts that would trigger code-switching would be anything that is external to the speaker: the participants in the conversation (Are both speakers L1 users?); the context (Is the conversation taking place in an English classroom? What is the goal of the interaction?); and topic (Is this discussion better communicated in the L1? Is the topic about an interaction the participants had in English?). Metaphorical contexts would be anything that is internal to the speaker: the emotion of the conversation (Is this an emotional interaction and the speaker is therefore more comfortable in the L1? Does the speaker feel uncomfortable in English?) and the fluency of the speaker (Does the speaker have the vocabulary or grammatical knowledge necessary for this conversation?).

Obviously, situational and metaphorical contexts interact quite a bit when the speaker is deciding when and how to code-switch. Turnbull and Dailey-O'Cain (2009) explain how much the speaker's identity also plays into this decision. Speakers often use code-switching to express familiarity toward one speech community, and/or distance 
from the other. Code-switching can be used to express the struggle that the speaker is going through to find and express their identity in either language. These metaphorical and situational contexts, as well as identity negotiation, are happening constantly in the mainstream classroom among ELLs.

It is not surprising, then, that in their essay on teacher and student use of the L1 in the foreign language classroom, Dailey-O'Cain and Liebscher (2009) explain that code-switching is a natural occurrence among bilingual people. Furthermore, code-switching is a sign that the student has substantial proficiency in both languages. Wei (2013) explains that code-switching is not a sign of deficiency in either language. To code-switch often requires considerable creativity and a wide working knowledge of both languages. MacSwan (2016) echoes this sentiment, explaining that code-switching shows advanced linguistic awareness.

Knowing that code-switching is natural and that it shows an aptitude for both languages, teachers of ELL students, even in a mainstream classroom, should feel that they are encouraged to use the students' L1s in their classroom. Lin (2015) states that to get the most educational benefit out of the L1, the teacher needs to intentionally integrate the L1 into key parts of the lesson. As will be discussed in the next section, that suggestion is relatively new to the world of English as a Second Language (ESL) education.

\section{History of Code-Switching in the Classroom}

The commonly held belief for many decades, beginning in the $1800 \mathrm{~s}$ and continuing through the mid-1900s, was that English should be isolated from the learner's 
L1 as much as possible. This belief was due to several underlying assumptions. The first was that since the L1 was learned without interference from another language, so too should English be learned without the L1. The second is that by compartmentalizing the languages the student would avoid confusing the two languages. Since the L1 is not useful in learning English, its presence was viewed negatively. This negative view is doubly reinforced as it became more and more commonplace for English to be taught by monolingual English teachers who might have internalized a mistrust for the culture and language that the students were bringing to the classroom. In these classrooms, the L1 is either directly banned, discouraged, or ignored; it is certainly not viewed as a part of a healthy classroom (Cook, 2001).

Vivian Cook (2001) studied the trend of code-switching in the classroom and charted its changes. She writes that in the later half of the 20th century, and especially in the 80 s and 90 s, scholars began to question those underlying assumptions and create models of how the two languages could exist side-by-side. Several of those new models include: the new concurrent method, Dodson's bilingual method, and Community Language Learning. Each model allows for the student to utilize the strengths that they have in their L1 and apply those strengths in English. Today, most scholars agree that code-switching has many benefits, even in a classroom where the teacher is monolingual in English. In my experience, many teachers who have not studied language acquisition still hold on to an antiquated view of the L1's place in the classroom and have not kept up with the research concerning its benefits. 


\section{Benefits of Code-Switching in the Classroom}

Before applying code-switching to the specific areas of reading and writing, this chapter will discuss the many benefits of code-switching that go above and beyond these two areas of content learning. Cook (2001) uses the term "multicompetence" to describe how bilingual students have several areas of expertise on which to draw. These areas include their L1, certainly, but it also includes their L1 culture and identity. To ignore these competencies is to automatically begin ELL students at a deficit, as students whose L1 is English are fully able to draw on their cultural knowledge and utilize all portions of their identity.

As stated in the definition section of this chapter, code-switching has sociolinguistic and socioemotional benefits. MacGregor-Mendoza (2005) states that when students work together in their L1, they also establish a common perspective on the activity. This helps to foster a working relationship among the students that might not have been achieved to the same degree if they had only been allowed to work in English. In a discourse analysis completed by Butzkamm (1998), 25 grammar school students worked together to apply background knowledge to a small group class discussion on a historical event. While completing this, they worked primarily in English, but would occasionally code-switch to German, their L1. He reported that as the students worked together they were able to build up each others' confidence by making sure the group is on the right track or are understanding each other fully. This research might also help to explain why students who share an L1 tend to build relationships with each other faster than with others. 
Beside these sociolinguistic and socioemotional benefits, the content is better understood and English production becomes more precise and accurate when students are allowed to collaborate in their L1 or consult L1 resources. These help when students are stuck on a lexical item or are unsure about vocabulary, and being able to use those resources helps students maintain fluency in output and flow of conversation (Butzkamm, 1998). Similarly, Cook (2001) states that the L1 can provide much-needed scaffolding and understanding checks. These benefits free up students' working memory (Turnbull \& Dailey-O'Cain, 2009) and allow students to use higher order thinking skills, as opposed to basic comprehension or translation skills. Alegria de la Colina and Garcia Mayo (2009) studied code-switching among undergraduates with low English proficiency during tasks of varying cognitive demands. They found that the students varied their strategies depending on the task, and that the L1 allowed them to transfer their cognitive, metacognitive, and social skills to English. In my own teaching practice, before knowing the research cited here, I have allowed students to switch between their L1 and English when needing to complete an activity quickly. Not only do students typically complete the task more quickly, but they often seem more confident in the product they've created.

With all of these benefits, it is clear that utilizing code-switching in the classroom can be a great asset to the learner as well as the teacher. However, along with these benefits, certain constraints need to be addressed as well.

\section{Limitations of Code-Switching}

Butzkamm (1998) in his study on how the L1 can be used as "conversational lubricant" (p. 81) cautions that when code-switching becomes concurrent translation (i.e. 
English is translated into the L1 immediately following the English input), the motivation to try to understand and use English may be lost. In a classroom with a monolingual English teacher, this could happen when students who share an L1 sit together and Student A translates any English input into the L1 for Student B. This is no longer effective code-switching, as Student A is not learning with or from Student B, and Student B is not attempting communication in English. Teachers, then, should place clear parameters around when code-switching is allowed and educate students on what effective code-switching looks like. For example, students might be allowed to code-switch when having small group discussions, but not during large class lectures.

Additionally, in a study of participants' eye movements during code-switching, Phillip and Huestegge (2015) found that students who frequently switch back and forth between their L1 and English might suffer from lower comprehension of the text overall. In a classroom with a monolingual English teacher, this kind of switching might occur if the student is allowed to consult a translation of the text side-by-side with the English version, or when the student is using a translator. Again, teachers should have clear expectations on how these resources will be used in the classroom. One possible solution could be that students are allowed to use L1 resources only after reading the English text once without L1 assistance, or only $x$ times per activity or time frame.

Along with instructional expectations and potential limitations, it is important to mention that students bring their own preconceived notions about how and when the L1 should be used in the classroom. These expectations should be addressed as well. In a survey of ELLs' perceptions of and attitudes toward English use in the classroom, 
Almohaimeed and Almurshed (2018) found that the advanced students reported wanting to use only English in the classroom, but beginner and intermediate students were more open to using the L1 in the classroom to aid learning and comprehension. This might be due to students having absorbed English-only ideologies and resisting using the L1, or students who are advanced English language users might view it as a point of pride that they do not need the L1.

\section{The English-Only Model}

If advanced students are apt to follow an English-only classroom model, then why should teachers avoid implementing this sort of policy? Beyond the benefits of code-switching, a classroom that eliminates code-switching entirely can cause serious issues for the students. Often called the "English-only" model, this classroom discourages the use of the L1 and sometimes even punishes students for using the L1 in any context, even one that serves learning. Many proponents of the English-only model suggest that this allows for maximum English input and English output, as well as increases motivation for learning English since it is the only way to communicate in that learning community. However, students also use the L1 to put English into context, thereby encouraging communication as a whole and increasing motivation (Turnbull \& Dailey-O'Cain, 2009). For example, students might find it useful to be able to draw parallels between an English construction and their L1. Additionally, allowing students to access their prior knowledge is a foundation of culturally responsive teaching (Hansen et al., 2013). 
Ultimately, by concentrating on an English mostly instead of an English only classroom, teachers will accomplish their ultimate goal for their students, that is, learning and using English fluently. When they leave the classroom, educators should want bilingual students to use both languages fluently, and the classroom allows students to practice these skills (Turnbull \& Dailey-O'Cain, 2009). In the "English-mostly" classroom, the focus then becomes to increase English input and output, not eliminate the L1. In a study of Turkish secondary school students, one hundred instances of code-switching were transcribed and analyzed. The results showed that students mostly used the L1 to help communicate better in English, either because they are debating the lexical item necessary in English or are helping to establish common understanding before continuing on with the task. Students, then, are not using the L1 as a way to avoid English, but rather as a way to facilitate conversation in English (Eldridge, 1996). The "English-only" model is, therefore, an outdated and ineffective pedagogy for a classroom whose intention is for the students to use English fluently.

\section{Reading Comprehension}

Teachers might have the natural inclination to avoid code-switching in reading activities, as code-switching can be seen as "cheating" at reading comprehension. After all, the teacher might think, the students aren't really reading in English. However, this view of reading comprehension does not account for students' L1 reading and comprehension skills, which could be much higher than they are in English. Using code-switching to teach and assess reading comprehension skills leads back to Cook's definition of "multicompetence," as referenced earlier in this chapter. If students are not 
allowed to use all of the competencies at their disposal, educators are restricting the students unnecessarily. To avoid doing this, this section will seek to explain best practices for using code-switching to aid reading comprehension. As teachers incorporate code-switching into reading activities, it is important to note that most measures of reading comprehension will naturally be in either a written or verbal form. This section will concentrate on improving reading comprehension regardless of how the reading comprehension is communicated, and the next section on writing skills will focus more on long-form writing activities.

Code-switching has been shown to significantly improve reading comprehension in English. Yeganepoor and Seifoori (2013) conducted a study in which students in their sophomore year of university were allowed to code-switch in pre-reading and post-reading activities. These were class-wide instruction and discussion, pair-work, and individual activities. Students who were allowed to code-switch during these activities scored higher on reading comprehension questions than the control group who was not allowed to code-switch. While some of these activities would not be able to be conducted by a monolingual teacher (large group discussion, for example), pair-work and individual activities could still be implemented by a monolingual teacher when students are being asked to read for comprehension.

Post-reading, students can work with others who share their L1 to process the English texts in a more meaningful way. Evans (2011) found that when students were allowed to use their L1 as they discussed English texts, they understood considerably more than if just allowed to use English. This improved comprehension could be 
attributed to the students being able to use their multicompetence. First, the students in Evans' study could access their L1 reading skills more easily when allowed to code-switch. Therefore, a student who might be reading at a lower level in English but a higher level in their L1 would be able to improve their English reading level merely by using code-switching while processing the text after reading it. This leads to the second competency which can be exhibited during code-switching: increased overall comprehension and comfortability with the text. The confidence that comes from understanding parts of the text can help students when analyzing the text overall, and understanding the text overall leads to better performance on comprehension assessments. Third, students are able to reduce their cognitive load during the processing period when allowed to code-switch. By freeing up space in their working memory, students can concentrate on more complex concepts, which can lead to more accurate and deeper analysis of the piece as a whole.

Code-switching can be used during reading as well. For example, by merely allowing students to look up English words in their L1, students will be able to compare the English text with their L1, thereby clarifying meanings of words or sentence structures. This reinforces the link between the L1 and English, which leads to deeper and longer lasting understanding of the word, and it also builds confidence in the student as they apply the newly clarified English word or structure to a larger context (Littlewood \& Yu, 2011). Additionally, using code-switching during reading as a paraphrasing tool can help aid reading comprehension. Hungwe (2019), studied first-year medical students as they attempted to decipher an article about the Human Genome Project, a text that was 
purposefully very difficult for these students to understand. The students read through the text on their own, then were encouraged to use paraphrasing with small groups in order to come to a deeper understanding of the text. The students were allowed to use any language in which they felt comfortable, so they naturally used code-switching often in their discussions. Even though this study was small and qualitative, the data suggest that the students improved their reading comprehension considerably after paraphrasing with their small groups, as their summary paragraphs of the article showed more comprehension of the text than they expressed when they originally were put into their groups.

Code-switching, when viewed as an aid to reading comprehension and not a way of circumventing "true" English reading comprehension, is truly an invaluable tool for any teacher who requires reading for their class. Many of these reading strategies can be used with texts in most any class: historical texts in history classes, literature in English classes, case studies in science classes, or word problems in math classes. What follows is often longer form writing assessments. After reading many different kinds of texts, some classes might assess their understanding with a writing project in which the students are expected to show not only how well they understood the text but also how well they can express their thoughts in writing, which is a whole different set of skills for the ELL student.

\section{Writing Skills}

More research has gone into code-switching and the writing process than reading comprehension. At each stage of writing, from the teacher's planning phase to prewriting 
and drafting, code-switching can be used to help students produce better quality writing projects. When teachers encourage L1 use during the writing process, students are able to make connections between their L1 and English, much like when they can use their L1 while reading, but writing has the additional benefit of being an output-focused activity. In output, students can practice using new vocabulary or structures repeatedly and in context, thereby solidifying the new vocabulary and skills. Moreover, students who use code-switching in the writing process can feel a sense of security in and ownership of their L1, which increases motivation for communicating those same thoughts in English (Littlewood \& Yu, 2011). Teachers who allow code-switching during the writing process are making space for ELL students to take ownership of English in ways that are meaningful for the student.

Even in a multilingual classroom with monolingual English students, teachers can plan to implement code-switching into their writing assignments for the benefit of those who can use it. In a review of the best code-switching practices in foreign language learning, Littlewood and Yu (2011) suggest that teachers incorporate students' L1s by choosing writing projects that draw on their L1 expertise. Such writing projects might include interviewing a person in their L1 community, such as a family member, friend, or community leader; or writing about students' personal experiences. In their instructional textbook on writing instruction for ELLs, Lenski and Verbruggen (2010) suggest allowing students to translate stories or folk tales from their L1 into English as a writing project in order to utilize students' L1 culture and language. These types of projects can easily be used for monolingual English students, while allowing ELL students to use their 
L1 in a meaningful way. Obviously, not all writing projects lend themselves to personal experiences or folk tales, but using these types of projects periodically during the school year, especially at the beginning of the school year when teachers are trying to get to know their students, can help bring about the educational and socioemotional benefits discussed in the introduction to this chapter's section on code-switching best practices.

Once the type of writing project is established, students enter a prewriting stage. This stage is a natural time to incorporate code-switching in any project. The purpose of prewriting is for the student to be able to build upon prior knowledge for the sake of further research and/or organization. For example, if the prewriting stage is calling for students to write down all they know about a topic, code-switching can be a useful way for students to focus on the content rather than vocabulary or sentence structures in order for them to express all that they know about the topic, not just what they know and can express in English. In a study of bilingual elementary students, Velasco and García (2014) analyzed the language used during the prewriting, drafting, and production stages. Students were not instructed to either use or not use code-switching, but instead they were free to complete the stages in whatever language they wished to use. Of the 24 writing samples taken, eight used code-switching, and five were further analyzed. Valasco \& García found that allowing code-switching allowed students to communicate thoughts that might have been more easily and thoroughly transmitted in their L1. This ability to maintain flow and fluency helped students develop their personal voice. Lenski and Verbruggen (2010) express a similar point about fluency. They suggest that students use code-switching to maintain the flow of writing during the prewriting process. Instead 
of needing to stop to look up a word or negotiate the structure, the student can continue with their brainstorming without interruption. These techniques help to keep the language barrier from interfering with the prewriting process, which can allow for deeper and more creative thought.

Similarly, in the drafting process, teachers can continue to allow students to code-switch to maintain flow and fluency. In the editing phase, students can come back to the bits of L1 and translate them into English using whatever resources they need, but they need not interrupt flow during the drafting process. Velasco and García (2014) also suggested that students keep track of the new English vocabulary they acquired during the drafting stage. To do this, students keep track of words that they are using in English that they want to incorporate into their English lexicon by noting the L1 translation next to the English word. By doing this, students are creating their own glosses, which are brief translations or explanations next to any new vocabulary. These glosses would be eliminated in the final draft, but until then, students are being repeatedly exposed to the new vocabulary alongside their L1 and in context, which helps the student to retain the new vocabulary.

All of these code-switching writing techniques can be easily integrated into a multilingual classroom with monolingual English students, as the students do not need teacher assistance to utilize them. Teachers could do a mini-lesson on these techniques at the beginning of the school year, then only need to encourage their use during other writing assignments. Even monolingual students could benefit from these techniques as they acquire new English vocabulary. These mini-lessons could have significant payoff 
for the ELL student in particular. Turnbull (2019) studied the overall effect of code-switching on the final draft of a writing assessment. His study consisted of 30 Japanese ELL first year university students who were split into groups to complete a writing assignment. Of the three groups, one did not allow any code-switching and the students relied entirely on English, one restricted code-switching to only specific parts of the process, and the third had no restrictions on code-switching during any part of the process. He found that students who used code-switching in the writing process scored higher than students who did not code-switch. These high scores were a result of their papers being better constructed and having fewer lexical mistakes. The research in this section supports code-switching at multiple stages of the writing process in order for students to develop English writing skills and produce higher quality writing overall.

\section{Summary}

This chapter defined code-switching, explored the history of code-switching in education, discussed the benefits and limitations of code-switching, and the disadvantages of the English-only model. It concluded with a description of the research-based best practices for code-switching in the areas of reading comprehension and writing skills, and explained the need for a specialized professional development in this area.

Code-switching has been shown to have academic and socioemotional benefits for students in the multilingual classroom, even when the teachers are monolingual. Code-switching for the purposes of this chapter and project as a whole was defined as using the L1 within words or between phrases or sentences. Students may engage in 
code-switching on their own or in groups with others of the same L1. Code-switching has sociolinguistic causes, which can roughly be divided into two main contexts as defined by Gumperz (1984): situational and metaphorical. Code-switching has not been always welcomed in the language learning classroom, but research in the late half of the 20th century through today strongly suggests that code-switching can help not only with content learning, but also English language acquisition.

Naturally, not all code-switching can be beneficial, as certain unrestrained uses of the L1 may lead to lower motivation to learn English or lower English comprehension. However, these potential disadvantages of code-switching in the classroom do not mean that the L1 should be banned in favor of an English-only classroom. English-only models do not allow for the motivation and socioemotional benefits that come from allowing code-switching, and can often have the opposite effect than what is intended, as students lose motivation and might miss out on connections between the L1 and English.

In order to use code-switching effectively in the classroom, especially for the purposes of reading comprehension and developing writing skills, teachers should follow best practices. For reading, that means allowing students to use translators sparingly and work with groups or pairs to summarize and analyze the piece. For writing, that means using code-switching to aid fluency and flow in prewriting and drafting stages, and using glosses for new vocabulary acquisition.

To answer the research question that began this chapter - How can code-switching be used in the mainstream high school classroom taught by monolingual teachers to enhance learning for ELL students in the areas of writing and reading comprehension? - 
the answer is to implement research-based best practices as outlined in the previous sections. Teachers should be educated in these best practices in order to teach their students how to use the L1 to their advantage, and how to avoid the pitfalls that were mentioned earlier in the chapter. These best practices can help students of any language background, even monolingual English students, and do not require the teacher to know the students' L1s. Implementing these best practices can help the student to be a strong bilingual person, who can use both languages in a variety of contexts both in and out of the classroom.

To that end, this project is a study of code-switching in the high school mainstream classroom among English language learners in order to find out how code-switching may help facilitate reading comprehension and development of writing skills. The purpose of this project is to collect information and best practices that can help monolingual educators understand how the L1 can be used in their classroom as a resource to enhance learning.

In the next chapter, I will outline a plan for professional development in which I can teach my monolingual colleagues these best practices and ask them to implement them in their classroom. A future goal is to present the results of these implementations in a qualitative analysis of the teachers' feedback. 


\section{CHAPTER THREE}

\section{Project Description}

This chapter gives a description of the professional development (PD) sessions that serve to answer the research question and present the findings to my colleagues. The research question being addressed is: How can code-switching be used in the mainstream high school classroom taught by monolingual teachers to enhance learning for ELL students in the areas of writing fluency and reading comprehension?

The first section describes the project as a whole along with the intended outcome. Within this section, I will address the setting, participants, and timeline for implementation. The second section explains the rationale and research behind the strategies used in these professional development sessions along with how the strategies will be used. It also contains how I will assess the effectiveness of the project.

\section{Project Overview}

The research presented in Chapter Two shows how beneficial code-switching in the mainstream classroom can be to facilitate reading comprehension, writing fluency, and socioemotional wellness. The primary benefits include: allowing for the entirety of students' abilities, including those in their L1 (Cook, 2001); easing of sociolinguistic and socioemotional stressors (MacGregor-Mendoza, 2005); and scaffolding for higher-order thinking (Turnbull \& Dailey-O'Cain, 2009). Research-based strategies for implementing code-switching in the classroom will be shared with teachers in order for them to apply best practices. To this end, I chose to create a series of three professional development 
sessions wherein I introduce the benefits of code-switching, teach the staff how to implement code-switching strategies, and follow up with their results.

The importance of teamwork, which will be further explored in the research framework section of this chapter, influenced me to select professional development sessions as a way to inform my colleagues of the benefits of code-switching. By meeting together in this way, we are able to exchange ideas easily, and the participants are held more accountable. Furthermore, during the ongoing COVID-19 pandemic, it is easy for teachers to become isolated from each other, as social gatherings and in-person meetings become less frequent. Even if this becomes a virtual meeting, the built-in opportunities for discussion allow for teachers to engage in much-needed collaboration. Collaboration also allows for teachers' to share their own professional experience and previous education on this topic.

This project adds to the conversation surrounding code-switching in the mainstream classroom by targeting monolingual teachers who have had little or no formal training in this area. Research shows that teachers who have not studied this area have many misconceptions about the effectiveness of code-switching, and often do not allow code-switching in the classroom (McMillan \& Rivers, 2011). This project will serve as a first step toward rectifying those misconceptions and creating a more research-based approach to L1s in the classroom.

\section{Setting}

The intended setting for these PD sessions are at a parochial middle and high school (grades 6-12) in the suburbs of the Twin Cities. The current student enrollment is 
472, of which 98 are English Learners (EL). The teaching staff at this school could be characterized as largely monolingual. There are 39 teaching staff, all of whom share English as an L1. Four teachers are fluent in at least one other language, though their interactions with students in that language are usually in a classroom context (i.e. the teachers are speaking Mandarin with students who are learning Mandarin, not with native Mandarin speakers).

Participants. The intended participants are the teaching staff mentioned above. The teaching staff is extremely homogeneous in training due to these factors: 1 . The school requires that the teaching staff are members of the same church body that the school is a part of; 2 . The school requires that teachers are thoroughly educated in the doctrine of the church body (called "synod certification"); and 3. There is only one college in the United States that trains teachers and also provides synod certification. Most of the teaching staff have attended this one college for their undergraduate degree. None of the teaching degrees offered through this college currently require students to take a course for teaching ELLs. Teachers who attended this college would have had to find ELL resources elsewhere. In a survey, only six teachers indicated that they have had formal training in the area of ELL education.

Even though the teachers are not formally trained in ELL strategies, the staff has been receiving PD in culturally responsive teaching (CRT) for the last three years. I plan to use CRT principles to help teachers understand the benefits of ELL teaching strategies, thereby encouraging teachers to invest in these sessions. 
The majority of teachers interact with ELL students while teaching a mainstream course where some students are monolingual in English and some have L1s that are not English. Those whose L1s are not English do not necessarily share the same L1, so the classroom can be characterized as multilingual. Second, the ELL students' English levels are, on the WIDA scale, anywhere from Level 3 (Developing) to Level 6 (Reaching). (See Appendices A and B for descriptors of these levels). While the participants teach a variety of subjects, the common factor among these subjects is that they require reading and/or writing as part of the course, so the techniques will concentrate on those two areas.

Inservice Environment. The PD sessions I developed are intended to take place during inservice days. Attendance for the teaching staff is mandatory, so I anticipate $100 \%$ participation, barring any who might be excused for the day. In order to allow for teachers to participate in a socially distant manner, I used Google Classroom as the platform to release video recordings of my presentations, discussion boards, and resources.

Technology. I chose Google Classroom as the platform for all the content, as we are a Google school and that platform is available on all devices. It also allows for the content to be viewed and interacted with asynchronously, which allows teachers to view the videos on their own time during the inservice days. I used Google apps for all the content, for ease in integrating into Google Classroom: Google Slides for the presentations, Google Classroom Questions for discussion, and Google Docs for handouts and breakout discussions. 
To record my presentations, I used the platform Loom. Loom allows me to use all the features of Google Slides with the addition of a video of my face in the corner. I want my audience to see my face, as I find these types of video presentations more engaging. Loom also allows participants to respond with emoji reactions and text responses, which allows for more interaction between the participants and myself.

The pre- and post-assessments are through Google Forms, again for ease but also because it allows for anonymity. I would like for teachers to be able to give their feedback anonymously, especially since the teaching staff is relatively small. Anonymity might encourage more honest feedback.

Timeline. The three PD sessions are intended to take place in the fall semester of the 2021-22 academic year. Each session will be about two months apart (one in August, one in October, and the final one in December). Each session is about 45 minutes in length. The goal of the first session is to facilitate buy-in from the faculty. The second session's goal will be to present teaching strategies and have teachers brainstorm how to use these strategies in their contexts. In the third session, the teachers will share with each other their results from implementing the strategies and give me feedback on how the strategies went. I will follow up the third session with a final feedback Google Form to ascertain if the strategies are still in use.

\section{Professional Development Framework}

The structure of the presentations are based on the principles put forth in Learning to Listen, Learning to Teach: The Power of Dialogue in Educating Adults (Vella, 2002). Vella starts her book with a list of 12 principles which guide adult learning. This section 
will focus on four of these principles: "Needs assessment: Participation of the learners in naming what is to be learned;" "Praxis: Action with reflection or learning by doing;" "Immediacy of the learning;" and "Teamwork: Using small groups" (Vella, 2002, p. 4).

In needs assessment, Vella (2002) explains that the instructor needs to determine the needs of the learners, and the learners should communicate their needs to the instructor. In doing this, motivation for learning increases as the adult learners understand how this lesson can apply to their own lives - in this case, their teaching. Vella points out that this conversation between instructor and learner should happen before instruction begins, so that the instructor can modify the lesson to meet the needs of those in attendance.

Vella goes on to explain the concept of praxis, or "action with reflection" (2002, p. 14). Praxis includes both inductive and deductive learning; in other words, the learners are applying their learning to particular instances as well as new or different situations. Vella writes, "When we set a group of adults to practicing a skill and invite them, as subjects, to analyze the quality of their practice, that moves practice to praxis" (p. 15). Therefore, it is not enough to merely present the learners with new skills or strategies; praxis calls for reflection on that skill and application to past and future situations.

A major principle of teaching adult learners is making sure the strategies can be immediately put into practice. Adults have much to occupy their time and therefore do not want to feel that they are wasting it on something that cannot apply to their situation immediately. Immediacy is therefore closely linked to perceived usefulness of the 
strategy. In order to prove usefulness and immediacy, the lessons presented should have a practical application that the participants can use in their lives without too much delay.

The final principle that I will address in this section is teamwork. Vella explains that teamwork helps to develop an atmosphere of safety and accountability. In order to maximize those qualities, participants should be allowed to pick their own groups as much as possible. Teamwork helps participants to explore complex and challenging ideas in a place where they will be supported.

\section{Implementation of Principles}

Each of Vella's (2002) principles mentioned above are put into practice during the sessions. Teachers are able to identify their needs in a brief pre-assessment Google Form, which will ask teachers the following questions: "What do you see as the benefits or drawbacks of students using their first languages during the learning process?", "Under what circumstances are students allowed to use their first language in your classroom?", "In the last week, approximately how many times have you encouraged students to use their first language to aid in their learning?", "What would you like to know about how to utilize students' first languages during learning?" These questions help me understand what the participants already know about code-switching, how and how often they are utilizing it in their classrooms already, and what they are interested in learning.

Teachers are able to use what they have learned immediately because the strategies are easily implemented in the classroom with little or no advance preparation. The strategies include suggestions like allowing students to research the story or concept online in their language or encouraging students to switch back and forth between 
English and their own language during writing. In order to help teachers even further, I provided sample lesson plans in each major content area. The lesson plans incorporate the techniques presented in the PD sessions.

Teachers are able to exercise praxis by applying the strategies to their teaching before and after implementation. This will be done mostly in small group discussion, which also allows for the benefits of teamwork. In these small group discussions, I direct their reflection by asking these general questions: "Share with each other a time when you used this strategy in your classroom. How did it go? What would you change?" Teachers also reflect on their experiences in a post-assessment Google Form, which includes these questions: "Which of the strategies mentioned in the presentation did you use?", "How successful were the strategies when implemented?", "If you were to use these strategies again, how would you modify them?", "How likely are you to try similar strategies in the future?" By asking teachers to think of their experience with using the strategies, I am leading teachers to praxis.

\section{Session Content}

I have an overall goal for each session: the first session is designed to encourage teachers to understand the importance of implementing code-switching. Because our staff is so under-educated in teaching ELLs, this session is very important to breaking down preconceived and outdated notions of the "English-only" model. While this school does not overtly subscribe to this model, personal conversations I have had with individual teachers shows me that some teachers still support this model. The second session introduces research-based code-switching strategies that teachers in any classroom can 
use. The third session is an opportunity for teachers to reflect on implementing the strategies.

The content of the first presentation is based on Culturally Responsive Teaching principles as described in the book Culturally Responsive Teaching and the Brain (Hammond, 2015). The teaching staff have read this book as part of past PD sessions, and so are familiar with the principles. By building on a foundation the teachers are already familiar with, I hope to encourage support from the faculty for the later session where I ask them to implement the new strategies. I start by revisiting the term "dependent learner" - a learner who counts on the teacher to "carry the cognitive load of the task" by waiting for the teacher to give overt hints or taking away the more difficult parts of the assignment (Hammond, 2015, p. 14). I then remind the teachers that many ELL students fall into this category, specifically in the areas of writing fluency and reading comprehension. I remind the faculty of one of the goals of CRT: to increase intellective capacity, which is "the increased power the brain creates to process complex information more effectively" (Hammond, 2015, p. 16). ELL students struggle to process complex information in English, and so one of our goals as teachers of ELs is to help them use their intellective capacity in English.

This is when I finally introduce the concept of code-switching along with the research that supports its use in the classroom. I start with how code-switching aids in higher order thinking tasks by freeing up working memory (Turnbull \& Dailey-O-Cain, 2009), then transition to the socioemotional benefits (MacGregor-Mendoza, 2005). I 
finish this presentation with a pre-assessment from the teachers which includes questions mentioned previously about what they already do and what they would like to learn.

The structure of the second and third PD presentations is based on one of the Cycles of Learning Designs from Janice Bradley's book Designing Schools for Meaningful Professional Learning (2015). The design of this cycle is used for "Creative and Innovative Teaching," the purpose of which is to try new strategies in the classroom, engage diverse learners, and problem-solve how to use the strategies effectively (Bradley, 2015, p. 63). This cycle has three stages: Planning, Inside the Classroom, and After the Lesson. The second PD session will address the Planning portion of the cycle, where teachers will identify which strategy they want to implement in their classroom, pose questions and concerns about implementation, and study research about best practices ( $\mathrm{p}$. $64)$.

In the second presentation I summarize the pre-assessment data, using it to introduce specific reading and writing strategies for ELL students. I allow time for teachers to discuss with their departments how they could use these strategies in their classrooms. The Inside the Classroom portion of this cycle takes place in the teachers' classrooms during one of their lessons, where teachers implement strategies of their choosing. Keeping in mind the restrictions of a monolingual teacher in a multilingual classroom, the strategies demonstrated in the PD are limited to those techniques that can be implemented without teachers using the students' L1s. Examples of these techniques are available in Appendix C. I also provide lesson plans in each of the major content areas that incorporate these strategies. 
The third session of PD follows the After the Lesson portion of the cycle, where teachers share their first impressions, discuss the outcome of the strategies, and reflect on the experience overall (Bradley, 2015). By doing this in small groups chosen by the participants, I hope to encourage honesty and accountability during these discussions. Participants should feel free to share their actual struggles and offer constructive criticism. I finish with a post-assessment, where teachers can reflect on how the strategies went and their effectiveness.

\section{Assessment}

The intended outcome of these presentations is to give teachers more strategies to use students' L1s to teach reading comprehension and writing fluency within their content areas. My goal is to see $75 \%$ of the teaching staff implement at least one strategy before the third session. I measure this with the post-assessment Google Form after the third session that contains these questions: "Did you use at least one of the strategies mentioned in the presentation? If so, which one(s)?", "How successful were the strategies when implemented?", "If you were to use these strategies again, how would you modify them?", and "How likely are you to try similar strategies in the future?" My goal is to see $30 \%$ of teachers using these strategies. The question about how the teachers have modified the strategies helps me to understand more fully how these strategies can be used in a wide variety of classrooms. I can use that information if I conduct this PD again in the future. 


\section{Summary}

The goal of the PD sessions outlined in this chapter were to answer the question: how can code-switching be used in the mainstream high school classroom taught by monolingual teachers to enhance learning for ELL students in the areas of writing and reading comprehension? The first part of this chapter described the participants and setting of the sessions: monolingual teachers with little ELL training during a mandatory inservice. The second part of this chapter outlined the framework for developing the PD sessions as well as a description of each inservice session.

By targeting monolingual teachers with little ELL training, these PD sessions will serve as a first step into future PD sessions on how to specifically serve the ELL population at this school. Code-switching is an easy way to make classrooms more inclusive, and it helps students to show how competent they are in so many areas other than English language processing.

In Chapter Four, I will reflect on the project as a whole, its potential for change and its limitations. I will then chart a map for where to go after this project in order to further my overarching goal of excellent education for ELL students at this school. 


\section{CHAPTER FOUR}

\section{Reflection and Conclusion}

In this chapter, I will reflect upon the experience of researching and creating the project. The purpose of this project was to answer this question: How can code-switching be used in the mainstream high school classroom taught by monolingual teachers to enhance learning for ELL students in the areas of writing fluency and reading comprehension?

I will begin the chapter by reflecting on what I have learned as a researcher, writer, and learner; as well as the areas of my literature review that were ultimately the most useful to my project. I will follow that with the immediate impacts of the project, including the project's limitations and how the project will be used. I'll finish by looking to the future of this project's impact - the possible policy implications, the benefits this project has for the teaching profession, and future project recommendations.

\section{Reflections on the Process}

The process of creating this project has helped me grow in many areas of my academic and professional life. It has certainly been an invaluable experience that has sparked my interest in many areas of ELL education that I had not previously considered.

First, I have had to improve my research skills in order to find the necessary information, both for writing the literature review and for creating the project itself. The first skill I had to master was Boolean searching techniques. It was important to include specific phrases around code-switching, while excluding terms that would take the searches in unnecessary directions. I was assisted by the research librarians at Hamline to 
help me understand how to use search engines to my advantage. The term "code-switching" itself was an obstacle as well, as the term is often not hyphenated or other terms are used to mean the same thing. It was important to cover all these possible search terms to find the necessary information.

In the area of research, the most important skill I learned was how to use an author's own references and bibliography to help me find related information. When I came across research that was near what I wanted but not quite, I would skim the bibliography or references page for articles that related more closely to what I was looking for. I would also do the reverse, searching for articles that cited an author whose work I found particularly useful. For example, Blake Turnbull was a researcher who had done extensive research in the area of code-switching. I searched for articles that cited Turnbull, and I used Turnbull's bibliographies to find other articles.

Second, I have learned much about being a learner. The biggest impact to my project was learning that I needed to choose an area of research that I found personally interesting and relevant to my setting. The research itself was much more engaging when I felt that I could implement what I learned the next day in my classroom. Another area that I had to learn more about was how different it is to teach adults - something I had to study for the project creation.

Ultimately, though, the most important thing I learned about myself as a learner was how to create motivation when I had little. It has been a difficult school year as a teacher. I have been teaching both online and in person all year, figuring out and maintaining COVID protocols, and trying to maintain a healthy emotional life during a 
time of immense stress and tension. In order to complete this project, I had to create time in my schedule to make progress without overextending myself. I created a habit of setting a timer for fifteen minutes per day when I would work on the project uninterrupted. Often I would only work for those fifteen minutes, but sometimes I would continue working as long as I had motivation to do so. Obviously, there were times when I had to work more than fifteen minutes whether or not I had the motivation, but on the whole, this technique helped me to make steady progress without overwhelming myself.

Finally, I have had to develop skills as a writer that I had not had to previously. As an English teacher with an undergraduate degree in Communication Arts and Literature, I have had to write a fair amount of papers. However, this was the longest writing project I have completed by far. I have had to learn how to maintain a consistent voice and tone throughout. I have also learned the importance of summaries, transitions, and review when writing a multi-chapter work. It has also been incredibly important to keep an accurate record of all the items in my references. Halfway through the process of creating this project, the APA manual was updated, which affected several of my citations. It was so important that I had kept an organized record of my references so that I could double check their accuracy. I used the resource NoodleTools.com to help with my references.

I have had to grow as a researcher, learner, and writer in the process of creating this project. In the next section, I will spend more time exploring which parts of the literature review were the most helpful in creating the project, as well as new connections to the literature. 


\section{Reflections on the Literature Review}

Several sources from the literature review served to be incredibly helpful when creating the project and shaping my understanding of the question itself. As stated in the previous section, Turnbull's research was pivotal in the research process, primarily Turnbull and Dailey-O'Cain's book First language use in second and foreign language learning (2009), which gave many practical strategies for using students' L1s in the classroom. This book, as well as other articles that did not make their way into my references page, were a jumping off point in finding other sources that addressed the same topics. Other sources that gave specific strategies for the classroom include Yeganepoor and Seifoori (2013), Evans (2011), Littlewood and Yu (2011), Hungwe (2019), Lenski and Verbruggen (2010), Velasco and García (2014), and of course Turnbull (2019). These were extremely helpful in developing the handout I created for the second session of my professional development series.

Other sources that helped to develop my understanding of my question include Cook (2001) and McMillan and Rivers (2011). Cook's term "multicompetence" was instrumental in establishing the importance of using students' L1s in the classroom. In the first session, this term was used to help the audience visualize how the L1 could be an asset, not a handicap. McMillan and Rivers' research explained that those who are not educated on how to teach ELLs usually have many misconceptions about how to teach ELLs. This research motivated me to pursue professional development as a project, as I wanted to correct any misconceptions that my colleagues might have. 
As I created the project, I made several new connections to that initial research. When I decided to create professional development, I wanted to connect it to previous professional development sessions our staff had gone through. The most recent professional development was in Culturally Responsive Teaching (CRT). When I created the first session, it became clear just how connected L1 use in the classroom is to CRT. Students' socioemotional well-being is directly related to their performance in the classroom. Part of supporting their socioemotional needs is including all of the student's competencies, including their L1 and the culture that comes with it. A second connection was just how interconnected the different areas of language arts are. I concentrated on reading and writing in this project, but after creating the project, it was clear to me that I could have easily included speaking and listening as well. Speaking and listening were present in each of the lesson plans I created, and many of the strategies I suggested could be easily extended to those areas.

Upon reflection, I have made new connections to my literature review and developed a deeper appreciation for some of the research presented in it. In the next section, I will explore the impact of the project in both short- and long-term.

\section{Implications}

\section{Short-Term Impact}

The professional development sessions presented in this project will be conducted in the 2021-22 school year at the school described in the project. The administration has already approved the sessions and specific dates are being chosen. Once the sessions are 
delivered, my hope is that teachers integrate more techniques into their classrooms that intentionally integrate students' L1s in a meaningful way.

While I am looking forward to leading this series of professional development, I am not unaware of the limitations of the project. As stated in the previous section, this project only addresses two areas of language arts: reading and writing. Listening and speaking are not explicitly addressed; as a result, the strategies presented are limited to certain parts of a teacher's lesson plans. This project also does not account for in-person coaching, which is significant in helping teachers develop new skills. Finally, in considering COVID protocols, I have not been able to develop as many in-person elements as I would have wished. The discussions are all virtual, which might be beneficial in some ways but does not allow for the same depth of conversation that in-person discussions might have.

\section{Long-Term Impact}

When considering the long-term impact of this project within the school I serve, I have high expectations for the conversations that this project will inspire. I hope that this project is the first step to eliminating English-only classrooms, potentially even leading to the ban of English-only policies outside of classrooms as well, such as in extra-curriculars or the dormitory program. I also hope that this is the first of many inservice opportunities that specifically address ELL education.

Outside of my school, the biggest benefit of this project is that it addresses monolingual teachers specifically, which is an under-researched area of L1 use in the classroom. Most of the sources I found assumed that teachers could communicate with 
their students in the L1, and that is not the reality of most classrooms with ELL students. Additionally, this project could also be used with multilingual classrooms, i.e. classrooms with students who have a variety of L1s.

Future projects that build upon this one could include a project with a similar structure that is aimed at speaking and listening instead of reading and writing. A similar project could also be done that addresses non-standard English dialects, such as African American Vernacular English (AAVE) or Chicano English. If these projects were done, my recommendations would be to focus on easy-to-implement strategies for teachers and to provide examples of lesson plans that implement the strategies. The project aim is to help teachers use the strategies, and simple strategies shown in practical lesson plans can increase the chance for the teachers to implement the strategies.

I would also suggest spending more time explaining to teachers the concept of nonstandard dialects, as there is arguably more stigma around using a nonstandard dialect than using an entirely different language. Teachers might need to learn that nonstandard dialects are not substandard before being open to allowing their use in their classrooms.

The long-term impacts of this project both in and out of my school setting give me hope for the future of L1 use in the classroom. In the next section, I will summarize this chapter and give my concluding thoughts.

\section{Conclusion}

As a researcher, learner, and writer, I have had to expand my skills in Boolean searches, more rigorous study habits, and long-form writing. I've revisited my research 
from the literature review and made new connections to the ideas presented there. I've reflected on the value of my project, both in the short and long term.

In Chapter One, I explained that my culture shock from teaching at a linguistically and culturally diverse school led me to study how best to serve students who were themselves going through a much bigger culture shock. Through this project, I learned more than I had anticipated about the importance of valuing my students' L1s. I am so thankful for all that I've learned, and I am excited to share what I know with my colleagues. I am looking forward to the responsibility of being the ELL expert at my school, so that we can provide a research-based, culturally responsive, and compassionate education to our ELL students. 


\section{REFERENCES}

Alegria de la Colina, A., \& Garcia Mayo, M. (2009). Oral interaction in task-based EFL learning: The use of the L1 as a cognitive tool. International Review of Applied Linguistics in Language Teaching, IRAL, 47(3/4), 325-345. http://doi.org/10.1515/iral.2009.014

Almohaimeed, M. S., \& Almurshed, H. M. (2018). Foreign language learners' attitudes and perceptions of L1 use in L2 classroom. Arab World English Journal, 9(4), 433-446. https://dx.doi.org/10.24093/awej/vo19no4.32

Bradley, J. (2015). Designing schools for meaningful professional learning. Corwin. https://doi.org/10.4135/9781483339269

Butzkamm, W. (1998) Codeswitching in a bilingual history lesson: The mother tongue as a conversational lubricant. International Journal of Bilingual Education and Bilingualism, 1(2), 81-99. https://doi.org/10.1080/13670059808667676

Cook, V. (2001). Using the first language in the classroom. Canadian Modern Language Review, 57(3), 402-423. https://doi.org/10.3138/cmlr.57.3.402

Dailey-O'Cain, J., \& Liebscher, G. (2009). Teacher and student use of the first language in foreign language classroom interaction: Functions and applications. In J. Dailey-O'Cain \& M. Turnbull (Eds.), First language use in second and foreign language learning (pp. 131-144). Multilingual Matters.

Eldridge, J. (1996). Code-switching in a Turkish secondary school. ELT Journal: English Language Teachers Journal, 50(4), 303-311. https://doi-org.ezproxy.hamline.edu/10.1093/elt/50.4.303 
Evans, M. S. (2011). Reading bilinguals reading: First language use and comprehension monitoring in the reading of different textual genres. New Zealand Studies in Applied Linguistics, 17(2), 53-69.

https://www.alanz.org.nz/wp-content/uploads/2018/11/NZSAL-Journal-172-2011. pdf\#page $=53$

Gumperz, J. J. (1984). Discourse strategies. Cambridge University Press.

Hammond, Z. (2015). Culturally responsive teaching and the brain. Corwin.

Hansen, A., Vásquez, A., \& Smith, P. (2013). Teaching language arts to English language learners. (2nd ed.). Taylor and Francis.

https://doi.org/10.4324/9780203081907

Hungwe, V. (2019). Using a translanguaging approach in teaching paraphrasing to enhance reading comprehension in first-year students. Reading \& Writing: Journal of the Reading Association of South Africa, 10(1), 1-9. https://doi.org/10.4102/rw.v10i1.216

Kamwangamalu, N. (2010). Multilingualism and codeswitching in education. In N. H. Hornberger \& S. L. McKay (Eds.), Sociolinguistics and language education (pp. 116-142). Multilingual Matters.

Lenski, S. D., \& Verbruggen, F. (2010). Writing instruction and assessment for English language learners K-8. The Guilford Press.

Lin, A. (2015). Conceptualising the potential role of L1 in CLIL. Language, Culture, and Curriculum, 28(1), 74-89. https://doi.org/10.1080/07908318.2014.1000926 
Littlewood, W., \& Yu, B. (2011). First language and target language in the foreign language classroom. Language Teaching, 44(1), 64-77. https://doi.org/10.1017/S0261444809990310

MacGregor-Mendoza, P. (2005). Bilingualism: myths and realities. In K. E. Denham \& A. C. Lobeck (Eds.), Language in the schools: Integrating linguistic knowledge into K-12 teaching (pp. 109-120). L. Erlbaum Associates.

MacSwan, J. (2016). Programs and proposals in codeswitching research: Unconstraining theories of bilingual language mixing. In J. MacSwan (Ed.), Grammatical theory and bilingual codeswitching (pp. 1-33). MIT Press.

McMillan, B. A., \& Rivers, D. J. (2011). The practice of policy: Teacher attitudes toward "English only". System (Linköping), 39(2), 251-263. https://doi.org/10.1016/j.system.2011.04.011.

Phillip, A., \& Huestegge, L. (2015). Language switching between sentences in reading: Exogenous and endogenous effects on eye movements and comprehension. Bilingualism: Language and Cognition, 18(4), 614-625. https://doi.org/10.1017/S1366728914000753

Turnbull, M., \& Dailey-O'Cain, J. (2009). Introduction. In J. Dailey-O'Cain \& M. Turnbull (Eds.), First language use in second and foreign language learning (pp. 1-14). Multilingual Matters.

Turnbull, B. (2019). Translanguaging in the planning of academic and creative writing: A case of adult Japanese EFL learners. Bilingual Research Journal, 42(2), 232-251. https://doi.org/10.1080/15235882.2019.1589603 
Velasco, P., \& García, O. (2014). Translanguaging and the writing of bilingual learners. Bilingual Research Journal, 37(1), 6-23. https://doi.org/10.1080/15235882.2014.893270

Vella, J. (2002). Learning to listen, learning to teach: The power of dialogue in educating adults (Rev. ed.). Jossey-Bass.

Wei, L. (2013). Codeswitching. In R. Bayley, R. Cameron, \& C. Lucas (Eds.), Oxford handbook of sociolinguistics. Oxford University Press. https://doi.org/10.1093/oxfordhb/9780199744084.013.0018

Yeganepoor, P., \& Seifoori, Z. (2013). The impact of code-switching on bilingual EFL learners' reading comprehension. Journal of English Language Pedagogy and Practice, 6(13), 167-179. 


\section{Appendix A}

\section{WIDA Performance Definitions Listening and Reading, Grades K-12}

\begin{tabular}{|c|c|c|c|}
\hline \multicolumn{4}{|c|}{ Within sociocultural contexts for processing language... } \\
\hline & Discourse Dimension & Sentence Dimension & Word/Phrase Dimension \\
\hline & Linguistic Complexity & Language Forms and Conventions & Vocabulary Usage \\
\hline \multicolumn{4}{|c|}{$\begin{array}{l}\text { Level } 6 \text { - Reaching } \\
\text { ange of grade-appropriate oral or written language for a variety of academic purposes and audiences. Automaticity in language } \\
\text { lentify and act on significant information from a variety of genres and registers. English language learners' strategic competence in } \\
\text { processing academic language facilitates their access to content area concepts and ideas. }\end{array}$} \\
\hline \multicolumn{4}{|c|}{ At each grade, toward the end of a given level of English language proficiency, and with instructional support, English language learners will process... } \\
\hline $\begin{array}{l}\text { Level } 5 \\
\text { Bridging }\end{array}$ & $\begin{array}{l}\text { - Rich descriptive discourse with complex } \\
\text { sentences } \\
\text { - Cohesive and organized, related ideas } \\
\text { across content areas }\end{array}$ & $\begin{array}{l}\text { - A variety of complex grammatical structures } \\
\text { - Sentence patterns characteristic of particular } \\
\text { content areas }\end{array}$ & $\begin{array}{l}\text { - Technical and abstract content-area } \\
\text { language } \\
\text { - Words and expressions with shades of } \\
\text { meaning across content areas }\end{array}$ \\
\hline $\begin{array}{c}\text { Level } 4 \\
\text { Expanding }\end{array}$ & $\begin{array}{l}\text { - Connected discourse with a variety of } \\
\text { sentences } \\
\text { - Expanded related ideas characteristic of } \\
\text { particular content areas }\end{array}$ & $\begin{array}{l}\text { - Complex grammatical structures } \\
\text { - A broad range of sentence patterns } \\
\text { characteristic of particular content areas }\end{array}$ & $\begin{array}{l}\text { - Specific and some technical content-area } \\
\text { language } \\
\text { - Words or expressions with multiple meanings } \\
\text { across content areas }\end{array}$ \\
\hline $\begin{array}{c}\text { Level } 3 \\
\text { Developing }\end{array}$ & $\begin{array}{l}\text { - Discourse with a series of extended } \\
\text { - Rentences } \\
\text { conted ideas specific to particular }\end{array}$ & $\begin{array}{l}\text { - Compound and some complex grammatical } \\
\text { constructions } \\
\text { - Sentence patterns across content areas }\end{array}$ & $\begin{array}{l}\text { - Specific content-area language and expressions } \\
\text { - Words and expressions with common } \\
\text { collocations and idioms across content areas }\end{array}$ \\
\hline $\begin{array}{l}\text { Level } 2 \\
\text { Emerging }\end{array}$ & $\begin{array}{l}\text { - Multiple related simple sentences } \\
\text { - An idea with details }\end{array}$ & $\begin{array}{l}\text { - Compound grammatical structures } \\
\text { - Repetitive phrasal and sentence patterns across } \\
\text { content areas }\end{array}$ & $\begin{array}{l}\text { - General content words and expressions, } \\
\text { including cognates } \\
\text { - Social and instructional words and expressions } \\
\text { across content areas }\end{array}$ \\
\hline $\begin{array}{l}\text { Level } 1 \\
\text { Entering }\end{array}$ & $\begin{array}{l}\text { - Single statements or questions } \\
\text { - An idea within words, phrases, or chunks } \\
\text { of language }\end{array}$ & $\begin{array}{l}\text { - Simple grammatical constructions (e.g., } \\
\text { commands, Wh- questions, declaratives) } \\
\text { - Common social and instructional forms and } \\
\text { parterns }\end{array}$ & $\begin{array}{l}\text { - General content-related words } \\
\text { - Everyday social, instructional and some } \\
\text { content-related words and phrases }\end{array}$ \\
\hline
\end{tabular}

Board of Regents of the University of Wisconsin System. (2017, February 6). WIDA

Performance Definitions Listening and Reading, Grades K-12 [Image]. Retrieved from

https://wida.wisc.edu/sites/default/files/resource/2012-ELD-Standards.pdf 


\section{Appendix B}

\section{WIDA Performance Definitions Speaking and Writing, Grades K-12}

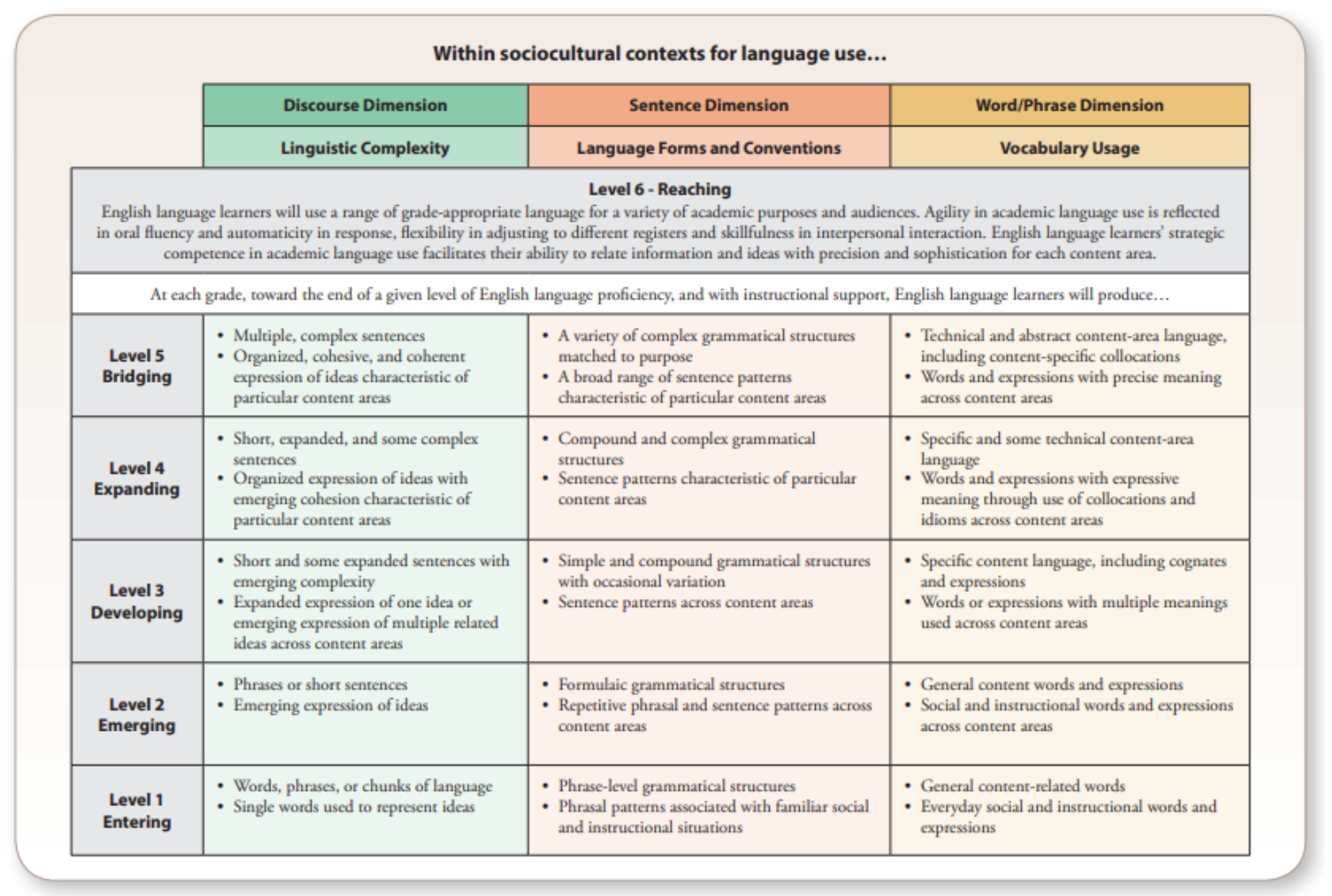

Board of Regents of the University of Wisconsin System. (2017, February 6). WIDA

Performance Definitions Speaking and Writing, Grades K-12 [Image]. Retrieved

from https://wida.wisc.edu/sites/default/files/resource/2012-ELD-Standards.pdf 
Appendix C

Handout -Practical Applications of Students’ First Languages in Your Classroom

\section{Practical Applications of Students' First Languages in Your Classroom \\ Reading \\ Pre-Reading \\ - Allow students to discuss anticipation questions in pairs or small groups that share a language \\ - Allow students to research the story or concept online in their language \\ - If the pre-reading assignment will not be graded, allow students to complete it in their own language \\ During Reading \\ - Allow students to take notes in their own language \\ - Allow students to ask each other questions about the text in their own language \\ - Have students create a multilingual glossary of terms \\ - Have students paraphrase what they read in their own language - either with a partner or in the margins of the text \\ Post-Reading \\ - Allow students to summarize or react to the reading or concept to each other in their own language}

\section{Writing}

Pre-Writing

- Allow students to complete brainstorming tasks using their own language

- Encourage students to conduct research in their own language (this can include interviews, videos, websites, books, anything!)

- For creative tasks, encourage students to draw on their culture for story ideas or structures

During Writing

- Encourage students to switch back and forth between English and their own language depending on their comfortability (of course, it should all be English by the time they hand it in, but this allows for more fluency as they write)

- Encourage students to create a personal glossary of words they had to learn during this activity

Your Turn: Are there other activities that you could use in your classroom that utilize your students' first languages in a way that helps to promote learning? In other words, what might first language use look like in your content area? 